\title{
Nanoparticles functionalized for target delivery of siRNA in Lung cancerous cells
}

Abstract: In the present medical field, scientists have designed new techniques to improve human health. These techniques focus on molecular level controls. Small interference RNA is an example of genetic control. This, together with Dicer and Argonaute 2 do not allow the transcription process to synthesize new protein. By using this mechanism, it is possible to control some diseases that are responsible for metastasis, such as lung cancer. Some experiments were conducted to prove the effectiveness of this technique. However, the problem is how to introduce the double-strand RNA to the cells. The issue was solved using nano-carriers as NP's. This paper aims at making a brief review of lung cancer, siRNA mechanism, and some different targeting techniques.

KeyWords: - siRNA, dsRNA, lung cancer, AGO2-Dicer complex, nanoparticles.

\section{Introduction}

Nowadays, Lung cancer remains the first cause of cancer death in the world ${ }^{1}$. It is estimated that just in 2012 , approximately 1.8 million people were diagnosed with lung cancer, leaving a more incredible figure of 1.6 million deaths, producing more deaths than breast, colon, and prostate cancer together. And they are commonly affecting male smokers ${ }^{2}$. Besides, another of the big enemies that we need to fight is metastasis, which is the cause of more than $90 \%$ of cancer deaths in the world. Metastasis is a multistep process by which cancerous cells colonize distant parts of the body (concerning the original site of the tumor growing) and also by which malignant cells became resistant or immune to cell apoptosis $^{3}$. It is essential to understand that day by day, and more people are going to increase these figures. Probably one of the main reasons for these alarming phenomena is due to the current procedures that are used to treat lung cancer patients, such as surgery, chemotherapy, and oral drugs, which remain ineffective or poorly effective. A few years Fire and Mello discovered RNA interference (RNAi), which has shown great potential in the treatment of a vast range of diseases in an innovative way, and within those diseases metastatic cancer. RNAi action processes could be defined as simple as the selective silencing of targeted genes ${ }^{4}$. Some problems that this relatively novel technique presents are related to the stability of the RNAi strands when those are inside the body and their capacity to bind the desired genes to avoid their expression correctly. In this way, many biological and artificial vectors were to achieve the "perfect carrier," a carrier that could overcome these barriers. Nanotechnology was one of the fields that many scientists around the world chose to develop it due to its huge range of possibilities of components, combinations and functionalization that could be performed to modify the properties of the final nanoparticles, their chemical stability and their relative low cost ${ }^{5}$. Here we present some of the most interesting procedures that combine these two technologies (RNAi or siRNA + Nanoparticles) to change the way that we deal with and how we treat lung cancer.

\section{Lung Cancer}

Cancer occurs when specific healthy cells begin to grow out of control. Cancer alters cell metabolism ${ }^{6}$. Commonly cancer cells develop due to damage in the DNA. Although this ${ }^{1}$ School of Biologicals Science and Engineering. Yachay Tech University, Ecuador.. damage can be controlled by cells specialized, in cancer cells, damaged DNA cannot be repaired, and these cells do not die. Generally, cancer cells look like a solid tumor, except in the case of leukemia. When these tumors are advanced, they enter the metastasis phase ${ }^{7}$. Metastasis is a complex process where tumor cells replicate out of control, thus expanding to other organs. Due to their functional structure, high vascularity, and high levels of oxygen lungs are perfect for developing metastasis because they provide a nutrient-rich environment ${ }^{8}$.

Cancer is the leading cause of death in the $21^{\text {st }}$ century. Lung cancer is the most frequently represented because it causes $18.4 \%$ deaths out of 9.6 million, mainly in males. ${ }^{1}$. The relation between smoking and cancer was first established in 1930 when clinicians identified this uncommon disease ${ }^{9}$. At present, the causes are: genetic or environmental. The genetic causes are DNA mutations and parental inheritance? Environmental carcinogens agents are smoking of cigarettes, air pollution, and occupational exposure ${ }^{10}$. The smoking intensity and average life are directly associated; therefore, this increases lung cancer².

Moreover, exposure to asbestos and radon also increases this possibility. There are two types of lung cancer: noncell lung carcinoma (NSCLC) and small cell lung carcinoma $(\mathrm{SCLC})^{11}$. Thus, it is essential to distinguish these types and the consequent treatment they need. Currently, there are some lung cancer treatments such as surgery resection, chemotherapy, immunotherapy, hormonal therapy, and radiotherapy ${ }^{7}$. Surgical resection is accepted for treating lung metastasis. However, it is not too useful because it only allows 5-year survival for patients ${ }^{8}$

In the present, a new type of treatment had been developed. It is called targeted therapy inhibitor, for example, Gefitinib. Gefitinib is an inhibitor that targets tyrosine kinase to epidermal growth factor receptor (EGFR). Another targeted therapy use liposomes with arginine. It is used to encapsulate human double-minute 2 (HDM2) gene to specific siRNA and low-density polyethylene (LPD) nanoparticles for delivery siRNA to lung cancer cells ${ }^{11}$. This alters the major cell-signaling and regulatory pathways ${ }^{10}$. Recent advances in cancer treatment are the use of small interfering RNAs $\left(\right.$ siRNAs) ${ }^{7}$. These molecules do not allow the replication process; therefore there is no synthesis of a new protein. 


\section{SiRNA mechanism}

Small interference RNA (siRNA), or also called posttranscriptional gene silencing (PTGS), is a biological mechanism that silences genes that affect the DNA replication process ${ }^{12}$ siRNA is a type of RNA interference with 21-23 nucleotides ${ }^{13,14}$ The phenomenon was discovered in the late 1980s in plants by Napoli et $a l^{14,15}$. Later, similar events were found in Caenorhabditis elegans ${ }^{16}$. They concluded that silencing the mechanism occurs because of mRNA degradation ${ }^{17}$.

Furthermore, the functions of siRNA are protected from viruses and defense against transposable or transposons genes $^{16}$. In mammal cells, the primary purpose is endogenous protection against cancer cells. This process differs in plants and mammals' cells. The first one is a transcriptional and posttranscriptional process, while the second one is only posttranscriptiona ${ }^{13}{ }^{13}$. Therefore genetic silencing is a novel method to limit transcription or active a sequence to degradation process $^{18}$

Gene expression is possible to interrupt a genetic speech with a process called genetic silencing ${ }^{19}$. It starts with the degradation of exogenous double-strand RNA (dsRNA) into siRNA by an enzymatic complex. siRNA hybrids the complementary regions of mRNA. When dsRNA is introduced into the cells, it interacts with Dicer. Dicer is an enzyme that cleavages the long double-stranded RNAs into shorter fragment (siRNA) ${ }^{17}$. These short fragments have an extreme nucleotide $3^{\prime}$ and $5^{\prime}$ free $^{13}$. These extremes are recognized by Argonaute 2 (AGO2), forming AGO2-RISC-Complex enzyme ${ }^{14,20}$. When this complex is built, siRNA is transformed into a single strand that guides the enzyme complex to mRNA. AGO2-RISC-Complex interacts with mRNA and cleavage it by Ago2 21,22. Finally, mRNA is degraded; thus, replication process is not allowed ${ }^{14}$. (Figure 1 )

siRNA is a molecular mechanism that shows the potential for the treatment of a disease such as cancer ${ }^{23}$. This technique is emerging as innovative nucleic acid treatment ${ }^{11}$. In contrast, traditional chemotherapy is widely accepted in the fight against metastasis. However, chemotherapy is harmful and toxic for the body giving the patient a lower quality of life ${ }^{8}$. Besides, chemotherapy affects not only malignant cells but also surrounding cells. Therefore, there is severe damage to the patient's body.

siRNA has high specificity, high efficiency, and low toxicity. Thus, it is a potential treatment for targeted genetic silencing ${ }^{8}$. However, siRNA is unable to enter into the cells without a transporter or nanocarriers. These transporters can be natural or synthetic ${ }^{12}$. Unaffected carriers can be viruses and bacteria, while synthetic transporters can be a self-assembled nanoparticle that is introduced in the tumor by intravenous administration ${ }^{24}$. The characteristics mentioned above make siRNA an efficient technology for oncology therapies because it allows us to silence specific genes, thereby stopping the protein synthesis ${ }^{12}$

\section{siRNA studies for cancer treatment}

As described above, siRNA opened a huge door in the fight against cancer because of its role in the regulation (downregulation) of the gene expression through sequence-specific post-transcriptional gene silencing ${ }^{25,26}$. Nonetheless, some of the main issues that siRNA silencing presents are: 1) The limited half-life of the uncovered strand of siRNA into the body due to the action of RNases and their low chemical stability in biological environments ${ }^{26}$. 2) The fact that systemic delivery of siRNA could produce adverse effects on the patient as liver toxicity and activation of immune responses. 3) The fact that it is practically impossible for the siRNA strands to enter the cell through diffusion due to its relatively large size and its negative charge $^{27}$

All these points made evident the necessity to develop a drug carrier that efficiently distributed the siRNA strands into

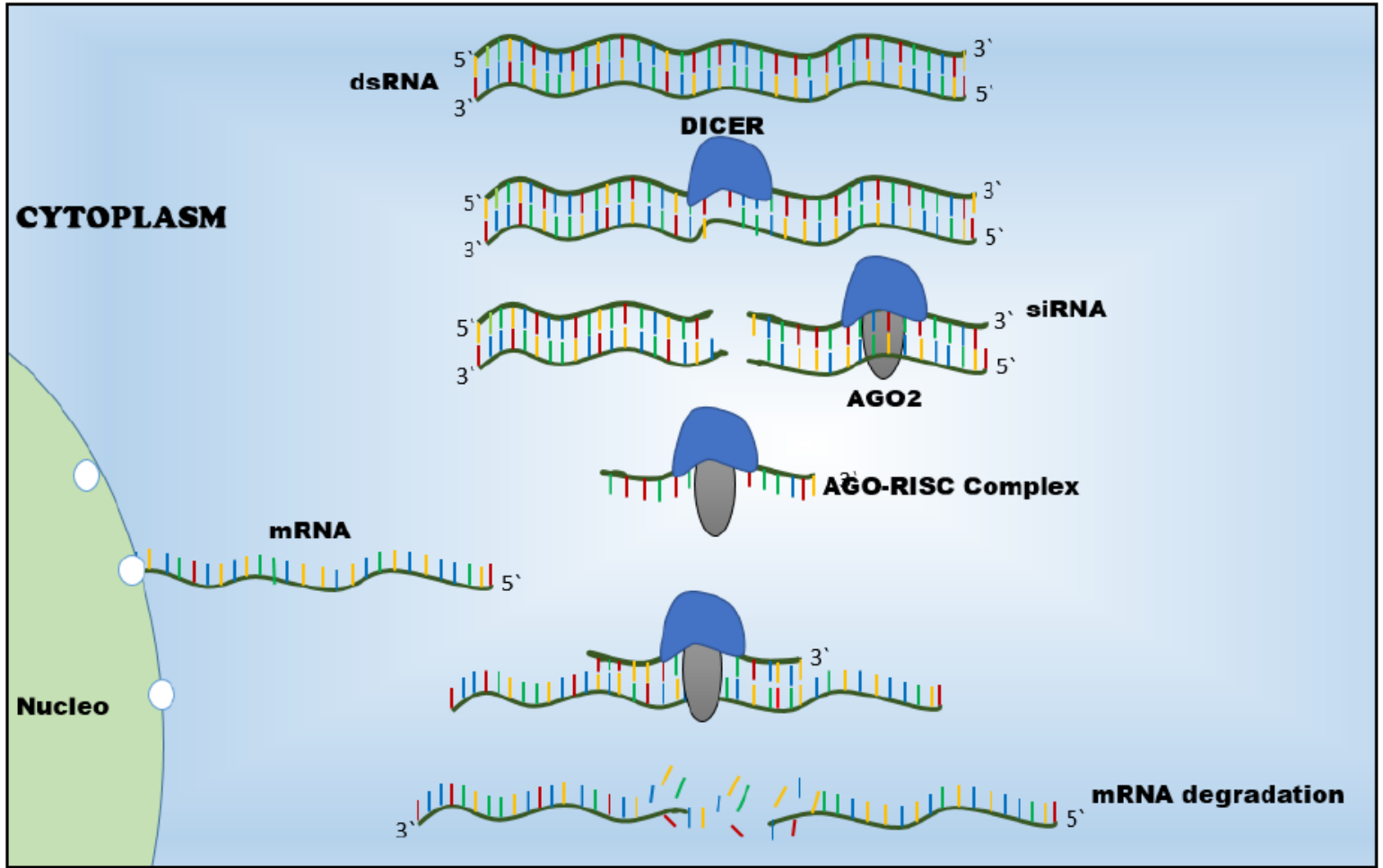

Figure 1. Gene silencing mechanism of siRNA. dsRNA is processed by Dicer into siRNA. After dsRNA is broken, Argonaute 2 interacts with it forming AGO-RISC Complex. siRNA guides these enzymes to mRNA because it has a site that recognizes mRNA. Later, AGO2 cuts mRNA, which finally is degraded, so there is not protein synthesis. 
the cancerous cells avoiding these barriers and minimizing the toxicity and the adverse effects in the patients ${ }^{28}$. There is where nanoparticles, liposomes, nanoplatforms, and nanotechnology, in general, came to have an essential role in the improvement of siRNA and its potential to affect cancer ${ }^{26,27}$. Since many target genes have been identified in lung cancer, until 2015, six clinical trials were undertaken with nanoparticle-based siRNA delivery systems ${ }^{29}$.

For this article, more than seven different cancer-targeting techniques were analyzed. These targeting techniques go from single gene targeting to more specialized techniques such as the work performed by Yang et al. in 2011 with a system that wants to affect a combination of ways to reduce tumor growth:

- Murine Double Minute 2 (MDM2) known as the significant suppressor of p53 function in cancerous cells ${ }^{30}$.

- The transcription factor c-myc that controls many essential functions within the cell as the cell cycle, the proliferation and sensitization to apoptotic stimuli ${ }^{31}$.

- Vascular Endothelial Growth Factor (VEGF) a growth factor that has been shown to play an essential role in the tumor angiogenesis, and metastasis ${ }^{32}$.
At the end of their investigation, Yang et al. reported

- $\quad$ A reduction in the tumor load of 20/30 (\%),

- Prolonged survival of $\sim 27 \%$, and that

- $-11 \%$ of the tumoral cells treated underwent apoptosis.

We also have the reports of Han et al. that synthesize SelfAssembled nanoparticles by the use of cationic bovine serum albumin (CBSA) with a significant reduction in lung metastasis, an increase in the proapoptotic activity and a notable decrease in cell proliferation ${ }^{33}$. As in the case of these three examples, all the procedures analyzed show positive results in the reduction or elimination of cancerous cells in the experiments carried out in vitro and in vivo, as can be seen in Table 1.

A remarkable job was performed by Davis et al. from 2008 to 2013 when the first official clinical trial was done by targeting the subunit M2 of Ribonucleic Reductase (RRM2) to reduce the growth potential of the cancer cells ${ }^{34}$. The hearing focused on solid tumors was probed in 24 patients and reported a decrease in the RRM2 mRNA up to $76 \%$. Despite these encouraging results, these techniques need to be improved and refined for future applications.

\begin{tabular}{|c|c|c|c|c|}
\hline $\begin{array}{l}\text { Drug or } \\
\text { Experiment }\end{array}$ & Type of siRNA delivery & Target & $\begin{array}{l}\text { Delivery } \\
\text { Method }\end{array}$ & Results \\
\hline CALAA-01 & $\begin{array}{l}\text { Cyclodextrin-based } \\
\text { polymer(CDP) }\end{array}$ & RRM2 & Iv. injection & $\begin{array}{l}\text { A decrease in the RRM } 2 \text { mRNA } \\
\text { up to } 76 \%\end{array}$ \\
\hline $\begin{array}{l}\text { siRNA/RGD } \\
\text { gold Np's }\end{array}$ & $\begin{array}{l}\text { Arginine-glycine-aspartic } \\
\text { acid (RGD) gold } \\
\text { nanoparticles }\end{array}$ & $\begin{array}{l}\alpha \mathrm{v} \beta 3 \\
\text { integrin }\end{array}$ & $\begin{array}{l}\text { Intratrachea } \\
1 \text { instillation }\end{array}$ & $\begin{array}{l}\text { A decrease in the incidence and } \\
\text { severity of the tumor clones, } \\
\text { tumor regression, } \sim 80 \% \text { increase } \\
\text { in survival. }\end{array}$ \\
\hline $\begin{array}{l}\text { Nano-based } \\
\text { inhalation } \\
\text { co-delivery } \\
\text { of anticancer } \\
\text { drugs. }\end{array}$ & $\begin{array}{l}\text { Lutein hormone-releasing } \\
\text { hormone (LHRH)-modified } \\
\text { mesoporous silica } \\
\text { nanoparticles (MSN) }\end{array}$ & $\begin{array}{l}\text { BCL2 } \\
\text { and } \\
\text { MRP1 }\end{array}$ & Inhalation & $\begin{array}{l}58 \% \text { of MRP1 silencing } \\
56 \% \text { of BCL2 silencing } \\
50 \% \text { and } 35 \% \text { downregulation in } \\
\text { pump and nonpump cellular } \\
\text { resistance respectively }\end{array}$ \\
\hline CBSA Np's & $\begin{array}{l}\text { Cationic bovine serum } \\
\text { albumin }\end{array}$ & $\begin{array}{l}\text { Not } \\
\text { specified }\end{array}$ & Iv. injection & $\begin{array}{l}\text {-Significant reduction in lung } \\
\text { metastasis, } \\
\text {-Increase in the proapoptotic } \\
\text { activity } \\
\text {-Notable reduction in cell } \\
\text { proliferation }\end{array}$ \\
\hline LPC Np's & $\begin{array}{l}\text { Lipid/Calcium/Phosphate } \\
\text { (LCP) }\end{array}$ & $\begin{array}{l}\text { MDM2, } \\
\text { c-myc, } \\
\text { VEGF }\end{array}$ & Iv. injection & $\begin{array}{l}\text {-Reduction on the tumor load } \\
\text { of } 20-30 \% \\
\text {-Prolonged survival of } \sim 27 . \% \text { - } \\
\sim 11 \% \text { of the tumoral cells } \\
\text { treated underwent apoptosis }\end{array}$ \\
\hline $\begin{array}{l}\text { Cationic } \\
\text { nano- } \\
\text { Lipoplexes }\end{array}$ & $\begin{array}{l}\text { Ethylphosphocholine-based } \\
\text { lipoplexes }\end{array}$ & Mcl 1 & $\begin{array}{l}\text { Intratrachea } \\
1 \text { Injection }\end{array}$ & $\begin{array}{l}\text {-Reduction of tumor nodules in } \\
\text { the lung tissue }\end{array}$ \\
\hline $\begin{array}{l}\text { Ph } \\
\text { responsive } \\
\text { Np's }\end{array}$ & $\begin{array}{l}\text { Poly (methacryloyloxy ethyl } \\
\text { phosphorylcholine)-block- } \\
\text { poly (diisopropanolamine } \\
\text { ethyl methacrylate) } \\
\text { (PDMA-b-PDPA) }\end{array}$ & MDM2 & $\begin{array}{l}\text { Tail vein } \\
\text { injection }\end{array}$ & $\begin{array}{l}\text {-Good biocompatibility. } \\
\text {-Significant induction of cell } \\
\text { death } \\
\text { - Inhibition of cell proliferation }\end{array}$ \\
\hline
\end{tabular}

Table 1. A summary of the procedures analyzed where specified: the drug or experiment used, type of siRNA delivery, target, delivery method, and the result obtained. 


\section{Conclusions}

RNA interference therapy is used to silence a selective gene expression. Thanks to this, it is possible to control the not healthy growth of tumor cells. dsRNA is introduced as exogenous genes that interact with Dicer getting siRNA. When AGO2 is linked, it forms AGO-RISC-Complex. siRNA server as a guide to the complex for attaching to mRNA. Finally, mRNA is degraded. As a result, the new protein cannot be synthesized. From the current review, we can conclude that although there is still entirely to investigate, siRNA is a reasonably powerful technique in the war against cancer and many other diseases for which we do not know a cure today. Nanotechnology also does not fail to present opportunities to promote innovative techniques for the development of biomedicine and health care.

\section{Conflict of interests}

The authors declare no conflict of interest, financial or otherwise.

\section{Bibliographic references}

1. Bray, F. et al. Global cancer statistics 2018: GLOBOCAN estimates of incidence and mortality worldwide for 36 cancers in 185 countries. CA. Cancer J. Clin. (2018) doi:10.3322/caac.21492.

2. Nasim, F., Sabath, B. F. \& Eapen, G. A. Lung Cancer. Medical Clinics of North America vol. 103 463-473 (2019).

3. Mehlen, P. \& Puisieux, A. Metastasis: A question of life or death. Nature Reviews Cancer (2006) doi:10.1038/nrc1886.

4. Davis, M. E. et al. Evidence of RNAi in humans from systemically administered siRNA via targeted nanoparticles. Nature 464 , 1067-1070 (2010).

5. Lohcharoenkal, W., Wang, L., Chen, Y. C. \& Rojanasakul, Y. Protein nanoparticles as drug delivery carriers for cancer therapy. BioMed Research International (2014) doi:10.1155/2014/180549.

6. Beger, R. A Review of Applications of Metabolomics in Cancer. Metabolites (2013) doi:10.3390/metabo3030552.

7. Sudhakar, A. History of Cancer, Ancient and Modern Treatment Methods. J. Cancer Sci. Ther. (2009) doi:10.4172/19485956.100000e2.

8. Yang, Y., Li, J., Liu, F. \& Huang, L. Systemic delivery of siRNA via LCP nanoparticle efficiently inhibits lung metastasis. Mol. Ther. 20, 609-615 (2012).

9. Witschi, H. A short history of lung cancer. Toxicol. Sci. (2001) doi:10.1093/toxsci/64.1.4.

10. Molina, J. R., Yang, P., Cassivi, S. D., Schild, S. E. \& Adjei, A. A. Nonsmall cell lung cancer: Epidemiology, risk factors, treatment, and survivorship. in Mayo Clinic Proceedings vol. 83 584-594 (Elsevier Ltd, 2008).

11. Oh, Y. K. \& Park, T. G. siRNA delivery systems for cancer treatment. Advanced Drug Delivery Reviews (2009) doi:10.1016/j. addr.2009.04.018.

12. van den Brand, D., Mertens, V., Massuger, L. F. A. G. \& Brock, R. siRNA in ovarian cancer - Delivery strategies and targets for therapy. Journal of Controlled Release (2018) doi:10.1016/j.jconrel.2018.05.012.

13. Ozcan, G., Ozpolat, B., Coleman, R. L., Sood, A. K. \& Lopez-Berestein, G. Preclinical and clinical development of siRNA-based therapeutics. Advanced Drug Delivery Reviews (2015) doi:10.1016/j. addr.2015.01.007.

14. Bernstein, E., Caudy, A. A., Hammond, S. M. \& Hannon, G. J. Role for a bidentate ribonuclease in the initiation step of RNA interference. Nature (2001) doi:10.1038/35053110.

15. Napoli, C., Lemieux, C. \& Jorgensen, R. Introduction of a chimeric chalcone synthase gene into petunia results in reversible co-suppression of homologous genes in trans. Plant Cell (1990).

16. Sen, G. L. \& Blau, H. M. A brief history of RNAi: The silence of the genes. FASEB Journal (2006) doi:10.1096/fj.06-6014rev.
17. Fire, A. et al. Potent and specific genetic interference by double-stranded RNA in caenorhabditis elegans. Nature (1998) doi:10.1038/35888.

18. Agrawal, N. et al. RNA Interference: Biology, Mechanism, and Applications. Microbiol. Mol. Biol. Rev. (2003) doi:10.1128/mmbr.67.4.657685.2003.

19. Baum, J. A. \& Roberts, J. K. Progress Towards RNAi-Mediated Insect Pest Management. in Advances in Insect Physiology (2014). doi:10.1016/B978-0-12-800197-4.00005-1.

20. Whangbo, J. S. \& Hunter, C. P. Environmental RNA interference. Trends in Genetics (2008) doi:10.1016/j.tig.2008.03.007.

21. Castel, S. E. \& Martienssen, R. A. RNA interference in the nucleus: Roles for small RNAs in transcription, epigenetics and beyond. Nature Reviews Genetics (2013) doi:10.1038/nrg3355.

22. Sarkies, P. \& Miska, E. A. Small RNAs break out: The molecular cell biology of mobile small RNAs. Nature Reviews Molecular Cell Biology (2014) doi:10.1038/nrm3840.

23. Xu, X. et al. Ultra-pH-Responsive and Tumor-Penetrating Nanoplatform for Targeted siRNA Delivery with Robust Anti-Cancer Efficacy. Angew. Chemie - Int. Ed. 55, 7091-7094 (2016).

24. Li, S. D., Chen, Y. C., Hackett, M. J. \& Huang, L. Tumor-targeted delivery of siRNA by self-assembled nanoparticles. Mol. Ther. 16, 163-169 (2008).

25. Conde, J. et al. Invivo tumor targeting via nanoparticle-mediated therapeutic siRNA coupled to inflammatory response in lung cancer mouse models. Biomaterials 34, 7744-7753 (2013).

26. Wall, N. R., Shi, Y. \& Shi, Y. For personal use. Only reproduce with permission from The Lancet. www.thelancet.com.

27. Shim, G. et al. Enhanced intrapulmonary delivery of anticancer siRNA for lung cancer therapy using cationic ethylphosphocholine-based nanolipoplexes. Mol. Ther. 21, 816-824 (2013).

28. Li, J., Yang, Y. \& Huang, L. Calcium phosphate nanoparticles with an asymmetric lipid bilayer coating for siRNA delivery to the tumor. J. Control. Release 158, 108-114 (2012).

29. Fujita, Y., Kuwano, K. \& Ochiya, T. Development of small RNA delivery systems for lung cancer therapy. International Journal of Molecular Sciences vol. 16 5254-5270 (2015).

30. Haupt, Y., Maya, R., Kazaz, A. \& Oren, M. Mdm2 promotes the rapid degradation of p53. Nature (1997) doi:10.1038/387296a0.

31. Miller, D. M., Thomas, S. D., Islam, A., Muench, D. \& Sedoris, K. c-Myc and cancer metabolism. Clinical Cancer Research vol. 18 55465553 (2012).

32. Holash, J. et al. VEGF-Trap: A VEGF blocker with potent antitumor effects. www.pnas.orgcgidoi10.1073pnas.172398299 (2002).

33. Han, J., Wang, Q., Zhang, Z., Gong, T. \& Sun, X. Cationic bovine serum albumin based self-assembled nanoparticles as siRNA delivery vector for treating lung metastatic cancer. Small 10, 524-535 (2014).

34. Heidel, J. D. et al. Potent siRNA inhibitors of ribonucleotide reductase subunit RRM2 reduce cell proliferation In vitro and In vivo. Clin. Cancer Res. 13, 2207-2215 (2007).

Received: 20 December 2019

Accepted: 20 April 2020 